\title{
Effect of EGR on Performances and Emissions of DI Diesel Engine Fueled with Waste Plastic Oil: CDF Approach
}

\author{
Khatir Naima ${ }^{1}$, Younes Menni ${ }^{2}$, Mounir Alliche $^{3}$, Giulio Lorenzini ${ }^{*}$, Hijaz Ahmad $^{5}$, Abdelkrim Liazid $^{6}$ \\ ${ }^{1}$ Department of Technology, University Centre of Naama - Salhi Ahmed, P.O. Box 66, Naama 45000, Algeria \\ ${ }^{2}$ Unit of Research on Materials and Renewable Energies, Faculty of Sciences, Department of Physics, Abou Bakr Belkaid \\ University, P.O. Box 119, Tlemcen 13000, Algeria \\ ${ }^{3}$ Renewable Energy and Materials Laboratory (LERM), Faculty of Technology, Department of Mechanical Engineering, \\ University of Medea, Medea 26000, Algeria \\ ${ }^{4}$ Department of Engineering and Architecture, University of Parma, Parco Area delle Scienze, 181/A, Parma 43124, Italy \\ ${ }^{5}$ Department of Basic Science, University of Engineering and Technology, Peshawar 25000, Pakistan \\ ${ }^{6}$ Faculty of Sciences, Department of Physics, Abou Bakr Belkaid University, P.O. Box 119, Tlemcen 13000, Algeria
}

\section{Corresponding Author Email: Giulio.lorenzini@unipr.it}

https://doi.org/10.18280/acsm.450304

Received: 5 January 2021

Accepted: 26 April 2021

\section{Keywords:}

waste plastic oil, fuel, diesel, EGR, injection timing

\begin{abstract}
Recently, there is an increasing interest in the pyrolysis of waste plastic into usable fuel as a friendly environment method for waste plastic disposal. The existing literature from various studies stated that the major problem related to the use of WPO in diesel engines is the high NOx emissions level. This paper aims to remedy this problem by suggesting the best EGR percentage with the advanced optimum injection timing. Primary, 5 EGR percentage fractions are considered: $0 \%, 5 \%, 15 \%, 20 \%$ and $25 \%$ percent. The results showed that $25 \%$ is the best percentage regarding emissions. However, a significant reduction in mean in-cylinder pressure, temperature, and heat release rate was depicted with the EGR fraction increase. Injection timing is advanced to recoup the decrease in performance. The results showed that $25 \%$ of EGR and advanced injection timing by 5 degrees would be better for performances and emissions of DI diesel engine while running with waste plastic oil as an alternative fuel.
\end{abstract}

\section{INTRODUCTION}

Nowadays, plastics are becoming increasingly ubiquitous. They are involved in agribusiness, commerce, sport, textiles, computers, automobiles...etc. [1]. Global plastics production reached a record 320 million tons in 2015 and could be double by 2050 [2]. The rapid population growth and the exponential increase in commercial products made from plastic waste disposal threaten the environmental ecosystem. Currently, plastic wastes are disposal by landfill, incineration, or recycling. For a long time, the landfill is considered as the most common method for post-consumer plastic disposal. However, this method cannot be a permanent solution since the landfill space is limited and require an increasing cost. On the other hand, incineration of plastic waste generates toxic and greenhouse gases with fly and bottom ashes and residues which require disposal [3].

Moreover, studies reported that about 4.8 to 12.7 million metric tons are thrown into oceans [4]. Consequently, it is found that about 60 to $80 \%$ of marine pollution is mainly caused by waste plastic [5]. Plastics waste is a cause of significant mortality in animals; associations estimate that about 100,000 marine mammals, one million birds, and more than 660 species are died each year by ingestion of plastic waste [6]. Beyond these consequences, plastics waste contaminates the human food chain and water ground leading to widespread diseases and the affection of soils and agricultural productivity [7]. Hence, it is necessary to find safer and proper waste plastic management methods. Pyrolysis seems to be the most promising technology permitting plastic waste conversion into valuable oil [8]. It has been found that these produced oils have similar properties to those of conventional diesel fuel and can be used as a fuel for diesel engines [9]. Until recently, there has been an increasing interest in using waste plastic oil as a fuel for diesel engines. The uses of waste plastic oil (WPO) as a fuel for direct injection (DI) diesel engine is studied only by a few researchers and remains a novel topic under investigation. Studies [8, 10-12] shown that the major problem related to the use of WPO as fuel is the high NOx emission level. For that reason, various solutions were presented. However, the combined effect of EGR with injection timing has not been extensively studied. Hence this paper aims to fill the existing literature gap by investing the effect of EGR and injection timing on the performances and emissions characteristics using CONVERGE CFD.

\section{METHODOLOGY}

A numerical investigation of WPO combustion in DI diesel engine was conducted to study the effect of EGR and $25 \%$ of EGR with different injection timing on the performances and emissions. The research was performed using the geometry of Lister peter TS1 engine parameters. The numerical study used the same engine model used by Naima et al. [8]. The engine 
was run at $1500 \mathrm{rpm}$ and full load with WPO and diesel without any modifications. Therefore, this study used the same engine operating parameters and specifications as given in Table 1. The properties of fuel used in this study are shown in Table 2. The study was conducted using CONVERGE CFD code, which was mainly developed for engine simulation, including combustion and emissions formation, to generate an orthogonal grid with auto-meshing and refining at run time.

Table 1. Engine details [8]

\begin{tabular}{cc}
\hline \multicolumn{2}{c}{ Engine characteristics } \\
\hline Bore and stroke & $95.3 \mathrm{~mm} \times 88.9 \mathrm{~mm}$ \\
\hline Connecting rod length & $165.3 \mathrm{~mm}$ \\
\hline Compression ratio & $18: 1$ \\
\hline Rated brake power output & $2.8 \mathrm{~kW}$ at $1500 \mathrm{rpm}$ \\
\hline Injector opening pressure & 250 bars \\
\hline Fuel injection timing & 20 degrees BTDC \\
\hline
\end{tabular}

Table 2. Fuels properties [8]

\begin{tabular}{lll}
\hline Property WPO Diesel & WPO & Diesel \\
\hline Density at $15^{\circ} \mathrm{C}(\mathrm{kg} / \mathrm{l})$ & 0.850 & 0.840 \\
\hline Kinematic viscosity at $40^{\circ} \mathrm{C}(\mathrm{cSt})$ & 2.11 & 0.840 \\
\hline LHV $(\mathrm{MJ} / \mathrm{kg})$ & 45 & 42.9 \\
\hline Oxygen content & 1.4 & 0.005 \\
\hline Cetane index & 62 & 53 \\
\hline Pour Point $\left({ }^{\circ} \mathrm{C}\right)$ & -7 & -2 to -12 \\
\hline Flash point $\left({ }^{\circ} \mathrm{C}\right)$ & 58 & 51 \\
\hline
\end{tabular}

CONVERGE has the adaptive mesh refinement AMR strategy, which automatically changes the mesh size during the simulation process to improve the calculation accuracy. Figure 1 presents the total mesh number during simulation, and Figure 2 reveals the computational mesh at $+23^{\circ} \mathrm{CA}$, showing the mesh refinement for a temperature around the flame front.

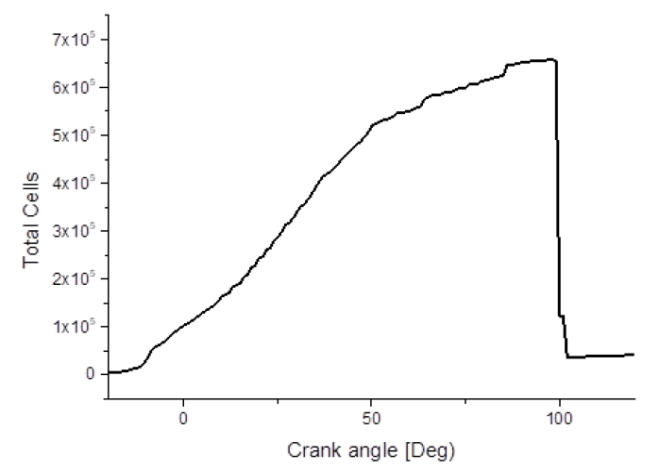

Figure 1. Total mesh number during simulation

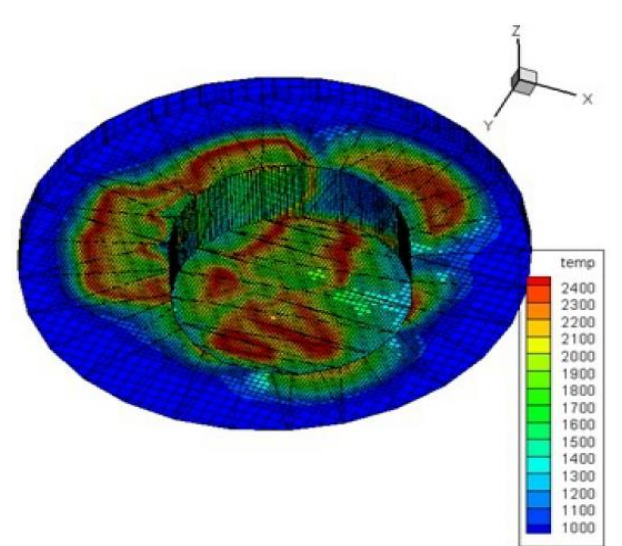

Figure 2. Computational domain at $+23^{\circ} \mathrm{CA}$ with temperature contours
The main models used in the current study are summarized in Table 3. Computations were performed in series on five cores and took approximately 32.83 hours for each fuel. From total CPU time, $77.73 \%$ is used for solving the transport equations, while $16.29 \%$ is used to move the surface and update the grid. The simulation study was performed on a direct injection compression ignition (DICI) engine. The used fuels are injected at a-20-crank angle (CA) before the top dead center (BTDC).

Table 3. The main physical models used in the current study

\begin{tabular}{cc}
\hline $\begin{array}{c}\text { Phenomena } \\
\text { Combustion model characteristic time } \\
\text { combustion }\end{array}$ & Physical models \\
\hline Turbulence model & (CTC) model \\
\hline spray breakup & RNG K-E \\
\hline Liquid injection & Blob cone injection \\
\hline collision & $\begin{array}{c}\text { NTC (No Time } \\
\text { Counter) }\end{array}$ \\
\hline Heat transfer & $\begin{array}{c}\text { wall Han and Reitz } \\
\text { model }\end{array}$ \\
\hline
\end{tabular}

The numerical study is carried out in two steps: First, to study the effect of exhaust gas recirculation on the combustion behavior of WPO, five EGR fractions were used: $0 \%, 5 \%, 10 \%$, $15 \%, 20 \%$, and $25 \%$. Secondly, for $25 \%$ of EGR, -20 and -25 BTDC injection timing is tested to recoup the no-EGR engine performances.

\section{VALIDATION OF THE NUMERICAL RESULTS}

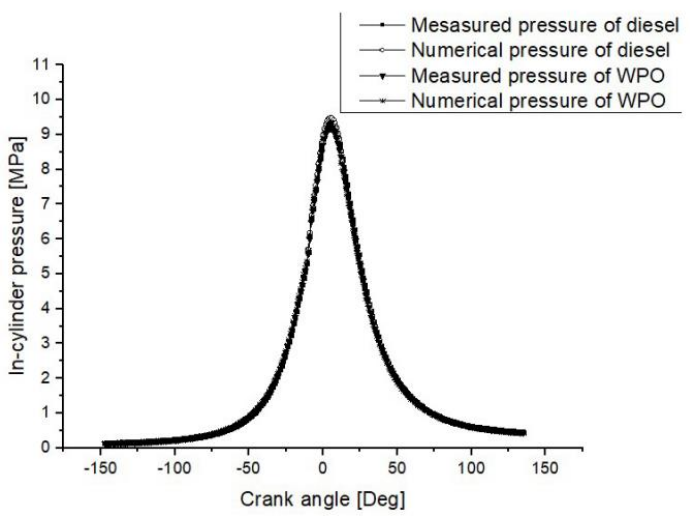

Figure 3. Validation of CFD pressure against experiment

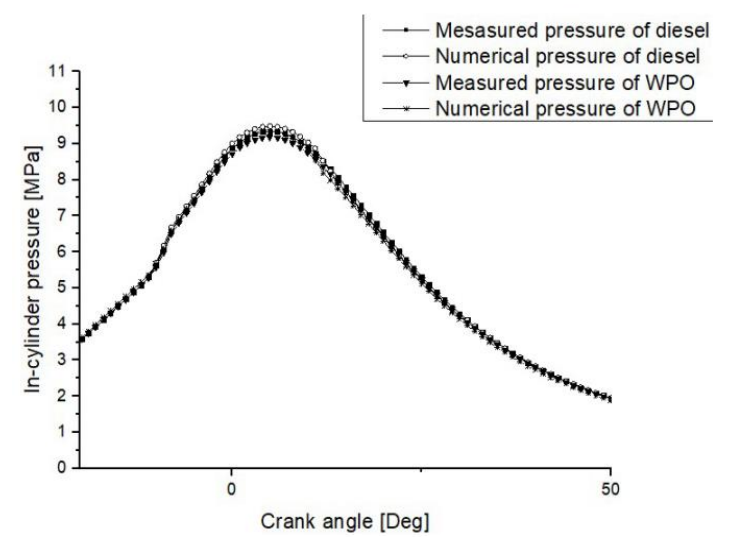

Figure 4. Zoomed view of CFD and experimental pressure 
Figures 3 and 4 show the computed and measured incylinder pressure. Excellent agreement was observed between numerical and experimental in-cylinder pressure for both fuels. The simulation follows the calculated in-cylinder pressure very well, and therefore the good choice of the numerical models is justified. Figure 4 shows a disparity at the start of ignition between experimental and numerical pressures. The disparity may be attributed to a slight miscalculation of temperature and pressure around the top dead center due to the misprediction of mixture formation and atomization during the injection process. The over-prediction shown in the zoom-out view shown in Figure 4 may also be due to RNG k-e model, that miscalculates the combustion mixing rate [13]. The divergence between measured and computed pressures is 1.34 bars for diesel and 1.44 bars for Waste plastic oil fuel. Figure 4 shows that the peak pressure of net diesel fuel is higher than that of WPO over 1,525 bars due to the longer ignition delay of diesel fuel. Longer ignition delay expands the amount of flammable air/fuel mixture taking part in the rapid combustion phase, resulting in higher peak pressure.

\section{RESULTS AND DISCUSSIONS}

\subsection{Effect of EGR}

Exhaust gas recirculation is a very efficient method of controlling NOx formation. Exhaust gases are mainly composed of carbon dioxide, nitrogen, etc., with high specific heat. The presence of exhaust gases in the intake mixture reduces the amount of oxygen available for combustion. Which, in turn, affects the air-fuel ratio [14]. The second impact of adding exhaust gases to the intake mixture is the increase in specific heat, which causes the flame temperature to decrease [15]. This arrangement between the reduced oxygen content and the reduced flame temperature dampens the rate of NO formation [16]. Figure 5 shows the evolution of pressure with the crank angle for EGR fractions from Figures 5 and 6 , indicating the variation of pressure and temperature with $5 \%, 10 \%, 15 \%, 20 \%$, and $25 \%$ of EGR. The addition of EGR reduces the mean in-cylinder pressure slightly. The higher heat capacity of air-EGR mixtures causing flame speed to reduce and, as a result, reduces the temperature and incylinder pressure [17].

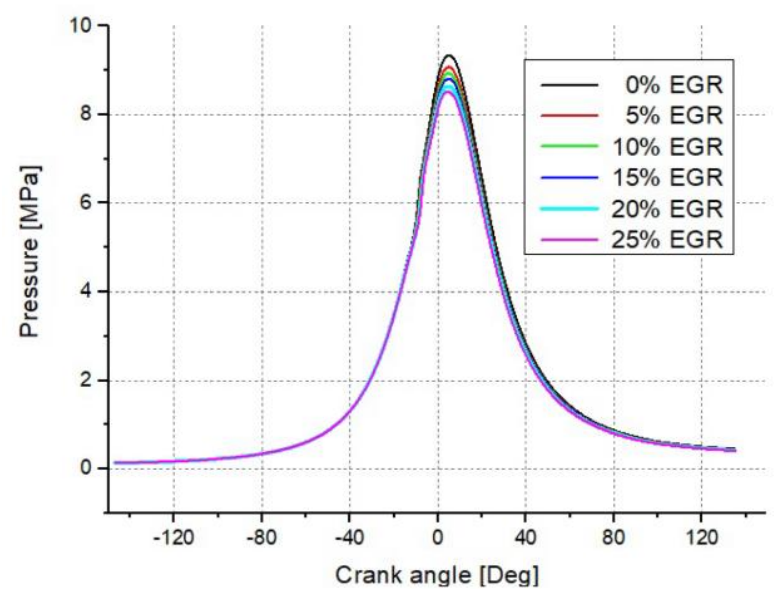

Figure 5. In-cylinder mean pressure evolution with different EGR fractions
Figure 6 shows that the mean in-cylinder temperature decreases with an increase in EGR percentage. This reduction is caused by the lower availability of oxygen involved in the combustion and the mixture's higher specific heat, as described earlier.

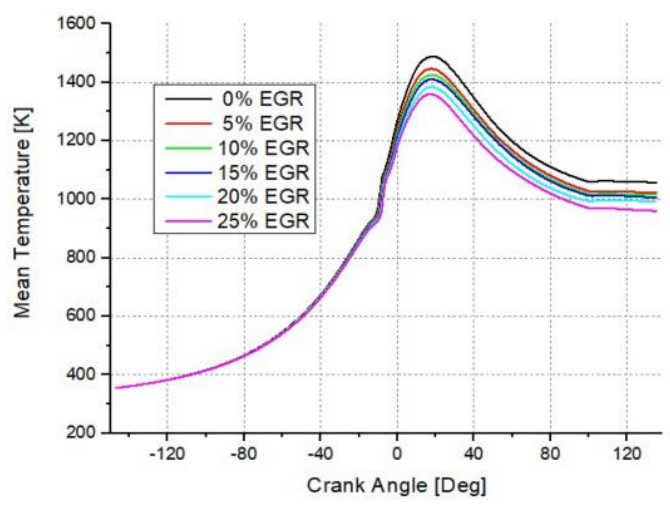

Figure 6. In-cylinder mean temperature evolution with different EGR fractions

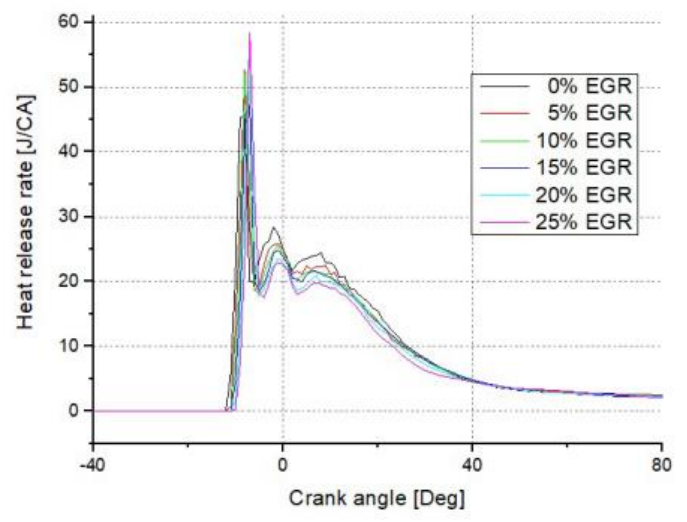

Figure 7. Heat release rate evolution with vs. EGRs

The reduced flame temperature and reduced mean incylinder temperature, also causing heat release rate and cumulative heat release to reduce, as shown in Figures 7 and 8. $\mathrm{CO}_{2}$ emissions are presented in Figure 9. By increasing EGR in the combustion chamber, $\mathrm{CO}_{2}$ emissions increase. This is due to the high quantity of $\mathrm{CO}_{2}$ emissions present in the recirculated exhaust gas. Carbon monoxide $(\mathrm{CO})$ and Hydrocarbons $(\mathrm{H})$ emissions are shown in Figures 10 and 11, respectively. $\mathrm{HC}$ and $\mathrm{CO}$ emissions increase with increasing EGR.

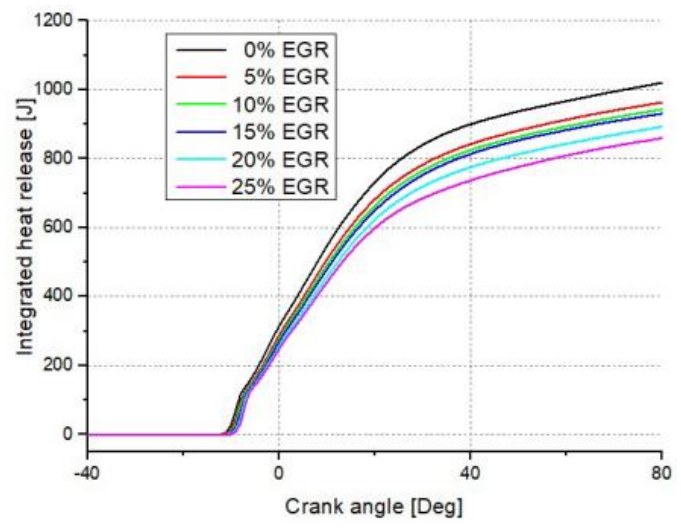

Figure 8. Integrated heat release evolution with different EGR fractions 


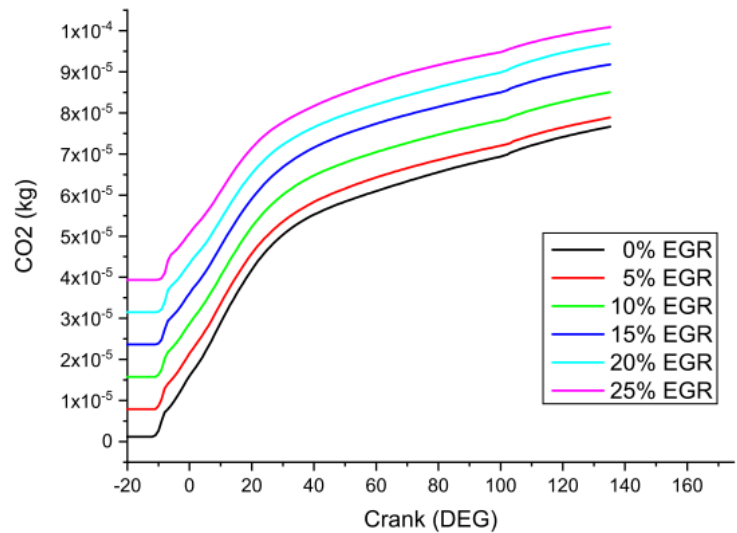

Figure 9. $\mathrm{CO}_{2}$ emissions with different EGR fractions

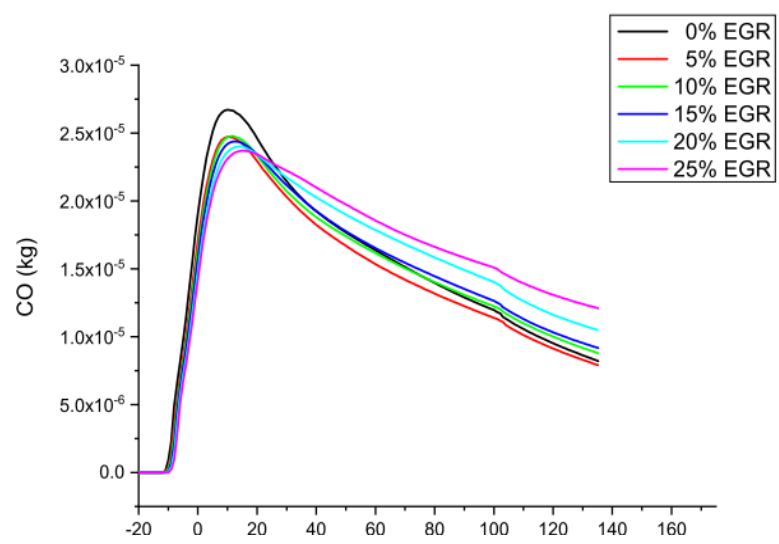

Figure 10. $\mathrm{CO}$ emissions with different EGR fractions

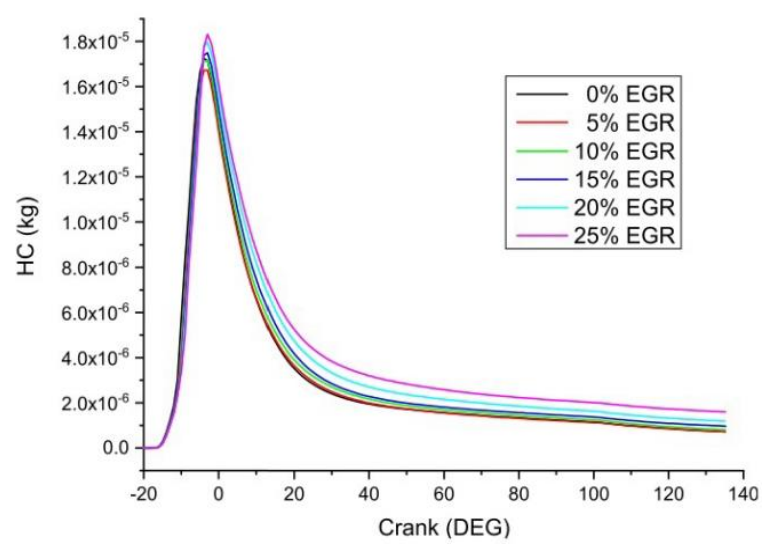

Figure 11. HC emissions with different EGR fractions

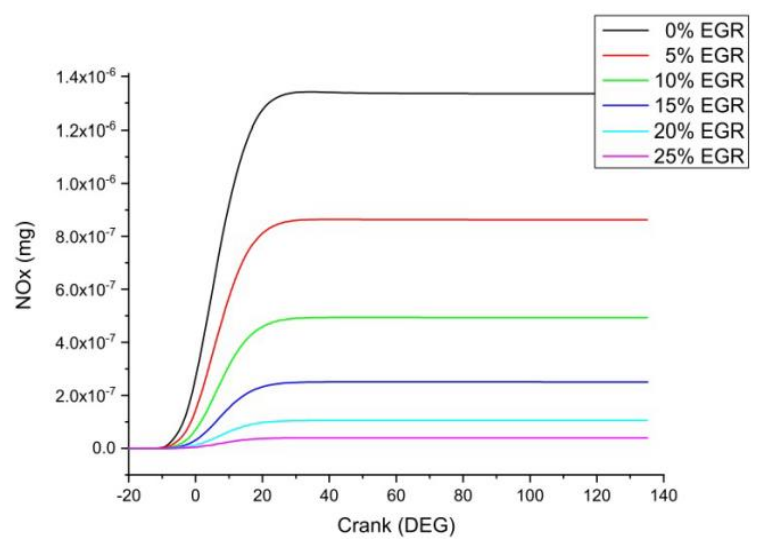

Figure 12. NOx emissions with different EGR fractions
Low oxygen availability in the combustion chamber results in rich local air/fuel mixtures. These regions with rich fuel/air mixture do not burn completely, which results in higher HC and $\mathrm{CO}$ emissions [18]. NOx Emissions with EGR are illustrated in Figure 12. NOx emissions are the overall production of $\mathrm{NO}$ and $\mathrm{NO}_{2}$ regrouped together. They are mainly formed from the combustion of atmospheric nitrogen. It is generally accepted that the significant factors causing the formation of $\mathrm{NO}_{\mathrm{x}}$ are strong high-temperature dependence and high oxygen concentration in the combustion chamber. Figure 12 shows clearly that $\mathrm{NO}_{\mathrm{x}}$ decreases with an increase in EGR fraction. This is attributed to the decrease in mean in-cylinder temperature and the reduction in $\mathrm{O}_{2}$ concentration caused by EGR addition.

\subsection{Effect of injection timing}

The second step is to study the impact of injection timing with an EGR of $25 \%$. The injection timing has been advanced from -20 to -25 . The comparative analysis between the results was made between (no-EGR, it $=-20),(25 \% \mathrm{EGR}$, it $=-20)$, $(25 \%$ EGR, it $=-25)$. Previous studies [15, 19-23] have shown that advances in injection timing led to increased peak pressure, thermal efficiency, and NOx emissions. Therefore, it would be evident that the injection advance catches up with reducing pressure caused by EGR.

Figure 13 shows that the peak pressure associated with $25 \%$ EGR is similar to that of no-EGR. A difference of only 1 bar was observed between the two cases. Advanced injection timing tends to increase the peak temperature slightly, as shown in Figure 14. However, the peak temperature remains below that without EGR. The difference in peak temperature is around $110^{\circ} \mathrm{C}$.

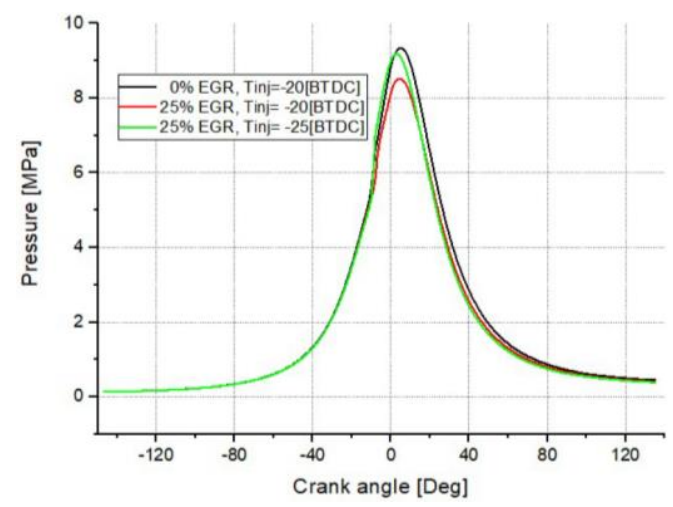

Figure 13. In-cylinder mean pressure with vs. ignition timing

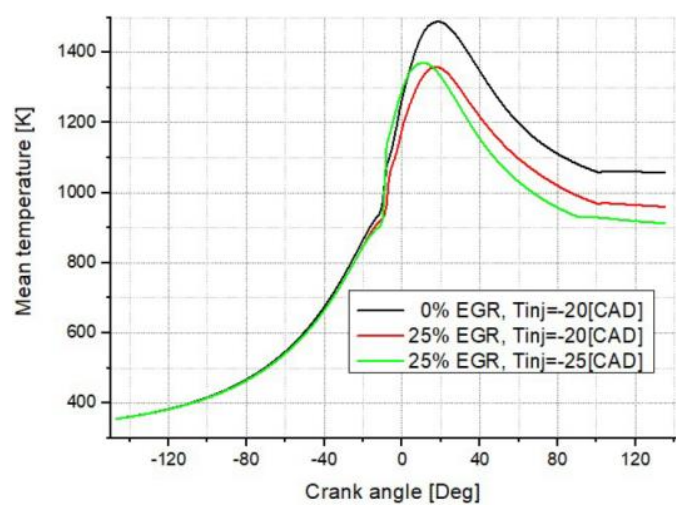

Figure 14. In-cylinder mean temperature with vs. ignition timing 


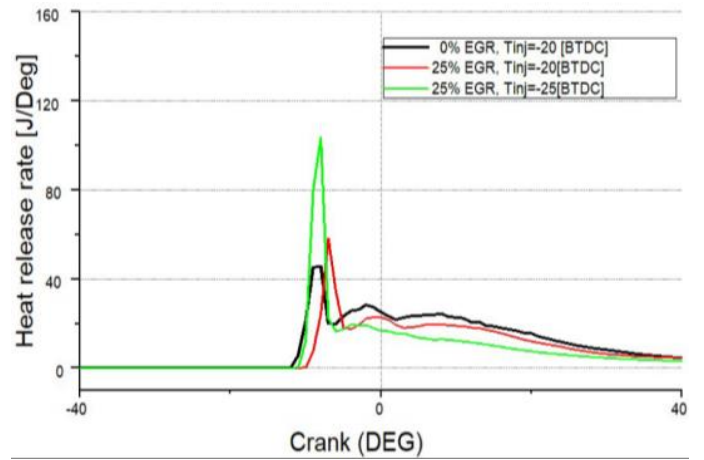

Figure 15. Heat release rate with various ignition timing

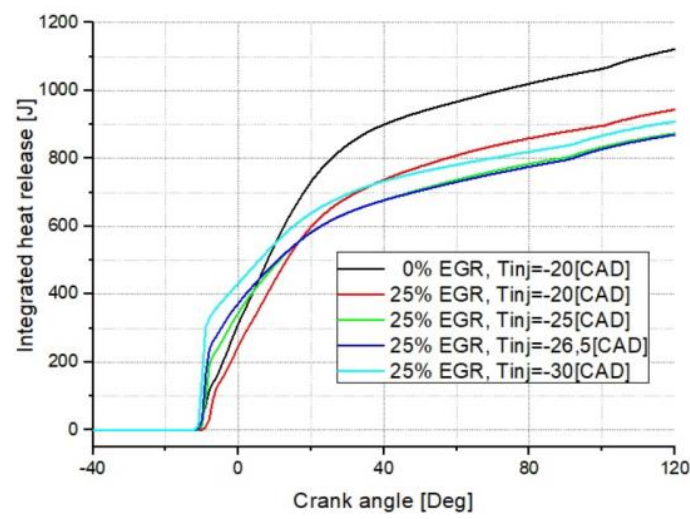

Figure 16. Integrated heat release with various ignition timings

This shows the advantage of using combined EGR on peak pressure and temperature. The two figures also show that the combustion is shifted towards the TDC. This effect is due to the advanced injection timing that increases the ignition delay period. Longer ignition delay increases the amount of mixture taking part in the rapid burning rate period increasing consequently the peak pressure and temperature. This effect is most apparent in Figures 15 and 16.

The evolution of the formation of $\mathrm{CO}$ and $\mathrm{CO}_{2}$ emissions is presented in Figures 17 and 18, respectively. $\mathrm{CO}$ emissions are intermediate products and mainly result from incomplete combustion. The engine produces more $\mathrm{CO}$ emissions under $\mathrm{it}=-25$ and $25 \%$ of EGR. This increase is not considerable, only $7 \%$ compared to the case of it $=-20$ and $25 \%$ of EGR. The CO 2 emission of it $=25$ and $25 \%$ of EGR is marginally lower by $5 \%$ than that of it $=-20$ and $25 \%$ of EGR.

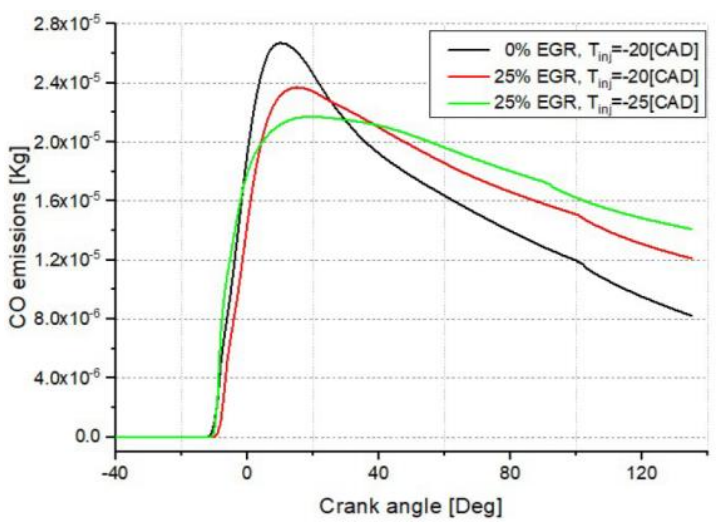

Figure 17. $\mathrm{CO}$ emissions with various ignition timing

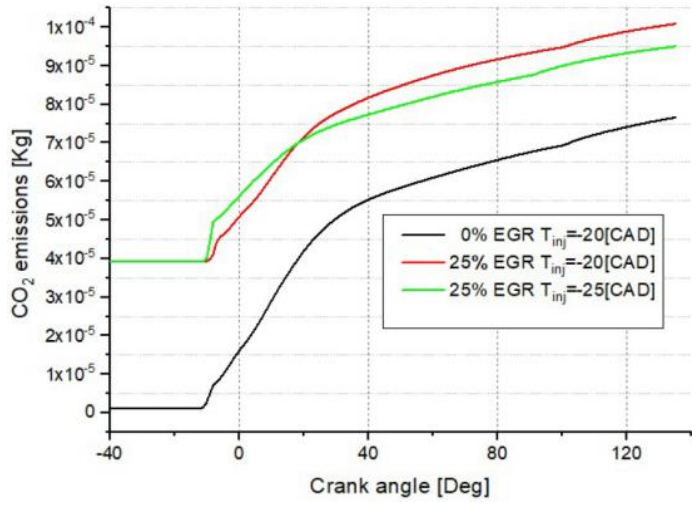

Figure 18. $\mathrm{CO}_{2}$ emissions with various ignition timing

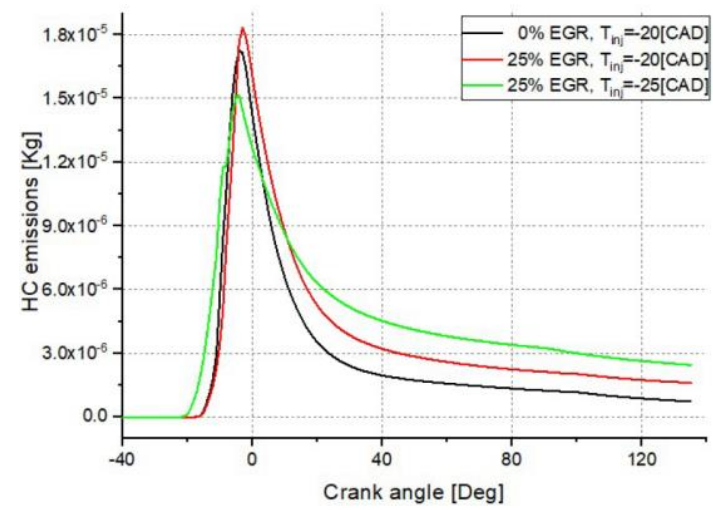

Figure 19. HC emissions with various ignition timing

Figure 19 shows HC emissions with a change in EGR and ignition timing. $\mathrm{HC}$ emissions are higher by $50 \%$ when the engine runs with $25 \%$ of EGR and it $=-25^{\circ} \mathrm{CA}$. Although in this case, the peak of $\mathrm{HC}$ emissions is lower, the reduced temperature prevents $\mathrm{HC}$ from continuing to burn, resulting consequently in higher $\mathrm{HC}$ levels.

NOx emissions are presented in Figure 20. The advance in injection timing raises the NOx slightly due to the moderate increase in temperature. However, this slight increase does not affect the positive effect of EGR on the significant reduction in NOx emissions.

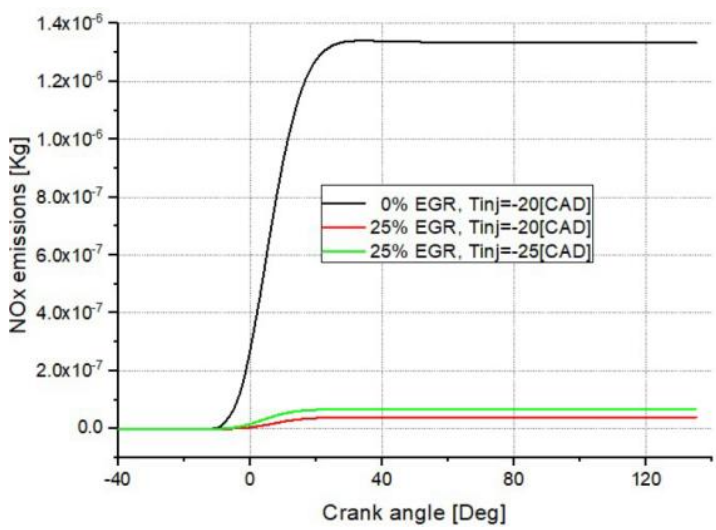

Figure 20. $\mathrm{NO}_{\mathrm{x}}$ with various ignition timing

\section{CONCLUSIONS}

This study aims to optimize the EGR ratio and proper 
ignition time of a DI diesel engine. The objective is to keep the performances of no-EGR and reduce the high $\mathrm{NO}_{\mathrm{x}}$ levels related to the use of WPO as fuel. The thermophysical properties of the WPO are considered. The main conclusions obtained from the current study may be summarized as follows:

- The addition of EGR reduces the mean in-cylinder pressure, temperature, and heat release rate due to the increase in the specific heat of the mixture of WPO/air, resulting in reduced combustion and flame speed. $\mathrm{CO}_{2}$, $\mathrm{HC}$, and $\mathrm{CO}$ emissions increase with increasing EGR ratio, while $\mathrm{NO}_{\mathrm{x}}$ emissions decrease. Near-ZeroEmission is obtained with $25 \%$ of EGR.

- Combined with EGR, advancing the ignition timing to $25 \mathrm{CA}$ has a beneficial effect on mean-in-cylinder pressure. While the in-cylinder temperature still lower comparing to no-EGR configuration. This effect is advantageous for keeping $\mathrm{NO}_{\mathrm{x}}$ at Near-Zero-Emissions.

- This study recommends $25 \%$ of the EGR ratio and advancing ignition timing by $5 \mathrm{CA}$ for maintaining the highest performances and solve the problem of increased $\mathrm{NO}_{\mathrm{x}}$ emissions levels associated with the use of WPO as fuel for diesel engines.

\section{REFERENCES}

[1] Das, P., Tiwari, P. (2018). Valorization of packaging plastic waste by slow pyrolysis. Resources, Conservation and Recycling, 128: 69-77. https://doi.org/10.1016/j.resconrec.2017.09.025

[2] Rochman, C.M., Browne, M.A., Halpern, B.S., Hentschel, B.T., Hoh, E., Karapanagioti, H.K., RiosMendoza, L.M., Takada, H., Teh, S., Thompson, R.C. (2013). Classify plastic waste as hazardous. Nature, 494(7436): 169-171. https://doi.org/10.1038/494169a

[3] Kassargy, C., Awad, S., Burnens, G., Kahine, K., Tazerout, M. (2017). Experimental study of catalytic pyrolysis of polyethylene and polypropylene over USY zeolite and separation to gasoline and diesel-like fuels. Journal of Analytical and Applied Pyrolysis, 127: 31-37. https://doi.org/10.1016/j.jaap.2017.09.005

[4] Jambeck, J.R., Geyer, R., Wilcox, C., Siegler, T.R., Perryman, M., Andrady, A., Narayan, R., Law, K.L. (2015). Plastic waste inputs from land into the ocean. Science, 347(6223):

768. https://doi.org/10.1126/science.1260352

[5] Aretoulaki, E., Ponis, S., Plakas, G., Agalianos, K. (2020). A systematic meta-review analysis of review papers in the marine plastic pollution literature. Marine Pollution Bulletin, 161: 111690. https://doi.org/10.1016/j.marpolbul.2020.111690

[6] Lestari, P., Trihadiningrum, Y. (2019). The impact of improper solid waste management to plastic pollution in Indonesian coast and marine environment. Marine Pollution Bulletin, 110505 https://doi.org/10.1016/j.marpolbul.2019.110505

[7] Owusu, P.A., Banadda, N., Zziwa, A., Seay, J., Kiggundu, N. (2018). Reverse engineering of plastic waste into useful fuel products. J Analytical and Applied Pyrolysis, 130:

285-293. https://doi.org/10.1016/j.jaap.2017.12.020

[8] Naima, K., Liazid, A., Tazerout, M., Bousbaa, H. (2018). Experimental and numerical investigation of combustion behaviour in diesel engine fuelled with waste polyethylene oil. Journal of Engineering Science and Technology, 13(10): 3204-3219.

[9] Singh, R.K., Ruj, B., Sadhukhan, A.K., Gupta, P., Tigga, V.P. (2020). Waste plastic to pyrolytic oil and its utilization in CI engine: Performance analysis and combustion characteristics. Fuel, 262: 116539. https://doi.org/10.1016/j.fuel.2019.116539

[10] Naima, K., Liazid, A. (2013). Waste oils as alternative fuel for diesel engine: A review. Journal of Petroleum Technology and Alternative Fuels, 4(3): 30-43.

[11] Ayodhya, A.S., Lamani, V.T., Thirumoorthy, M., Kumar, G.N. (2019). NOx reduction studies on a diesel engine operating on waste plastic oil blend using selective catalytic reduction technique. J Energy Institute, 92(2): 341-350. https://doi.org/10.1016/j.joei.2018.01.002

[12] pal, S., Chintala, V., Kumar Sharma, A., Ghodke, P., Kumar, S., Kumar, P. (2019). Effect of injection timing on performance and emission characteristics of single cylinder diesel engine running on blends of diesel and waste plastic fuels. Materials Today: Proceedings, 17: 209-215. https://doi.org/10.1016/j.matpr.2019.06.420

[13] Naima, K., Liazid, A., Bousbaa, H. (2018). Numerical simulation of combustion behavior of DI diesel engine with conjunction of AMR and embedding refinement strategies. Journal of the Society of Automotive Engineers Malaysia, 2(2): 112-126.

[14] Heywood, J.B. (2018). Internal Combustion Engine Fundamentals (2ed.). McGraw-Hill Education.

[15] Damodharan, D., Sathiyagnanam, A.P., Rana, D., Kumar, B.R., Saravanan, S. (2018). Combined influence of injection timing and EGR on combustion, performance and emissions of DI diesel engine fueled with neat waste plastic oil. Energy Conv. Management, 161: 294-305. https://doi.org/10.1016/j.enconman.2018.01.045

[16] Deng, J., Wang, X., Wei, Z., Wang, L., Wang, C., Chen, Z. (2021). A review of NOx and SOx emission reduction technologies for marine diesel engines and the potential evaluation of liquefied natural gas fuelled vessels. Science of the Total Environment, 766: 144319. https://doi.org/10.1016/j.scitotenv.2020.144319

[17] Praveena, V., Martin, M.L.J. (2018). A review on various after treatment techniques to reduce NOx emissions in a CI engine. $J$ the Energy Institute, 91(5): 704-720. https://doi.org/10.1016/j.joei.2017.05.010

[18] Patil, V., Thirumalini, S. (2020). Effect of cooled EGR on performance and emission characteristics of diesel engine with diesel and diesel-karanja blend. Materials Today: https://doi.org/10.1016/j.matpr.2020.10.303

[19] Rami Reddy, S., Murali, G., Ahamad Shaik, A., Dhana Raju, V., Sreekara Reddy, M.B.S. (2021). Experimental evaluation of diesel engine powered with waste mango seed biodiesel at different injection timings and EGR rates. Fuel, 285: 119047 https://doi.org/10.1016/j.fuel.2020.119047

[20] Subramani, S., Natarajan, K., Lakshmi Narayana Rao, G. (2021). Optimization of injection timing and antioxidants for multiple responses of CI engine fuelled with algae biodiesel blend. Fuel, 287: 119438. https://doi.org/10.1016/j.fuel.2020.119438

[21] Sun, Z., Cui, M., Nour, M., Li, X., Hung, D., Xu, M. (2021). Study of flash boiling combustion with different fuel injection timings in an optical engine using digital 
image processing diagnostics. Fuel, 284: 119078. https://doi.org/10.1016/j.fuel.2020.119078

[22] Ye, Y., Gao, W., Li, Y., Zhang, P., Cao, X. (2020). Numerical study of the effect of injection timing on the knock combustion in a direct-injection hydrogen engine. Int J Hydrogen Energy, 45(51): 27904-27919. https://doi.org/10.1016/j.ijhydene.2020.07.117
[23] Kulandaivel, D., Rahamathullah, I.G., Sathiyagnanam, A.P., Gopal, K., Damodharan, D., Melvin Victor, D.P. (2020). Effect of retarded injection timing and EGR on performance, combustion and emission characteristics of a CRDi diesel engine fueled with WHDPE oil/diesel blends. Fuel, 278: 118304. 